\title{
Unemployment in Greece: Econometric Evidence after the Athens 2004 Olympics and before the Global Financial Crisis of 2007-2009
}

\author{
Stavros Rodokanakis \\ Department of Social and Policy Sciences, University of Bath, Claverton Down, Bath BA2 7AY, UK \\ Correspondence should be addressed to Stavros Rodokanakis, srodo2003@yahoo.gr \\ Received 4 September 2012; Accepted 21 September 2012 \\ Academic Editors: D. M. Hanink, B. M. Tabak, and E. Yeldan
}

Copyright (c) 2012 Stavros Rodokanakis. This is an open access article distributed under the Creative Commons Attribution License, which permits unrestricted use, distribution, and reproduction in any medium, provided the original work is properly cited.

This paper investigates the probability of employment in Greece and focuses on 2006, namely, well after the Athens 2004 Olympics and its fiscal stimulus and before the eruption of the global financial crisis of 2007-2009 that transformed into an economic and sovereign debt crisis with unprecedented consequences in the country's postwar economic history. Based on microdata from the Labour Force Survey, the analysis depicts the impact of gender, age, marital status, area of residence, level of education, and immigrant status on finding a job, in Greece as a whole and the two most populated Greek regions, Attica and Central Macedonia. The findings of the logit model show differences in the three areas under examination mainly among the educational variables and area of residence.

\section{Introduction}

The aim of the paper is to study the impact that various social and demographic characteristics had on the labour market in the Greek regions of Attica and Central Macedonia, and the entire country, in 2006- the year before the global financial crisis of 2007-2009. The year 2006 is well after the Athens 2004 Olympic Games and its fiscal stimulus, and before the eruption of the financial crisis that developed into an unprecedented economic and sovereign debt crisis for Greece. We will see the prospects of employment in the Greek labour market even during the period of rapid economic growth and in any case before the recent debt and economic crisis of Greece.

We choose Attica and Central Macedonia because the above regions are the largest in Greece in terms of population, and the two biggest urban agglomerations in the country (Athens and Thessaloniki) are situated in the regions under study, and compare them with the whole of Greece.

The main questions to be answered are first, what are the social and demographic characteristics that increase the chances of someone in the examined population to find a job, and, second, whether university graduates face greater difficulties in finding a job than nonuniversity degree holders; this issue is of great importance, since earlier studies (see $[1-5]$ ) have shown this peculiarity in the Greek labour market.

We test the human capital theory; namely, we try to research whether the more educated a person is, the higher the probability of him finding a job is. Previous labour market studies for Greece were based on qualitative research and Labour Force Survey (LFS) aggregated data. Our analysis of investigating the unemployment risk in the Greek labour market-at national and Nomenclature of Territorial Units for Statistics (NUTS) 2 level-is based on the microdata of the Greek LFS. The access to the individual anonymised records of the Greek LFS was not allowed to researchers until the summer of 2005, due to the Data Protection Act.

The paper starts discussing unemployment in Europe and Greece, and the macroeconomic indicators of Greece focusing on the recent fiscal and investment bottlenecks, and the problem of shadow economy in the country; we also refer to the macroeconomic data of the examined areas. Then, we discuss the econometric method we follow and 
refer to the descriptive statistics of the variables we use in the model. We run a logit model for the year 2006based on microdata of the Greek LFS - for the three areas under study. The paper concludes with the impact of the socioeconomic variables used on employment probability in the examined areas and ends with some general comments on the merit and value of this study, and the prospects for further research.

\section{Unemployment in Europe and the Examined Areas}

In Greece, in the years 1988-1998 (the percentage of unemployment is characterized by an augmentative tendency from 1988 to 1998 with the exception of the two-year period 1989-1990, during which it shows a temporary decrease) the unemployment rate climbed from $7.7 \%$ in 1988 to $11.5 \%$ in 1998 (on the basis of Eurostat figures, unemployment in 1998 was $10.8 \%(1997=9.6 \%)$. However, on the basis of the definitions used up until 1997, the unemployment rate in 1998 was $11.5 \%$ ) (LFS). In 1995 the unemployment rate in Greece passed the 10\% mark for the first time in the second half of the century [6]. Unemployment in Greece is now a structural phenomenon of considerable dimensions and with a particular dynamic that tends to keep it going. According to Eurostat data, the unemployment rate in the EU-15 increased from $8.2 \%$ in 1991 to $10.9 \%$ in 1996 [7]. The unemployment rate in Greece rose above the EU average for the first time in 1998, and the gap was spreading, since the EU average was falling and the unemployment rate in Greece was still rising [8].

Tables 1(a) and 1(b) indicate that Greece had the highest unemployment rate from both the EU and Euro area averages; only Attica in some cases appears to have lower levels of unemployment than the EU and Euro area means. Concerning long-term unemployment (LTU) all three Greek areas under examination had higher LTU rates in comparison to the two European multiareas in all three years.

\section{Greece in the European and World Economy: Macroeconomic Data of the Examined Areas}

3.1. Greece as a Whole. According to 2001 census the population of the entire Greece was 10.96 million [9]. In 1988 , Greece's GDP was equal to $58 \%$ of the EU-12 average, whereas in 1996 the country improved its position since its GDP was $68 \%$ of the EU-15 mean and $82.2 \%$ of the EU25 mean in 2004 (source: [10]). In 2008 the Greek GDP (PPP) per capita was $80 \%$ of the EU-15 [11]. Greece (from 2000 onwards) and Ireland (from the early 1990s onwards) had the highest GDP growth rates in the EU-15 until the global financial crisis of 2007 [7]. Also, according to the UN classification of human development index-which was released on December 18, 2008 and covers the period up to 2006-Greece was ranked 18th in the world and 11th in the EU. Central Greece, Southern Aegean, and Attica are the richest regions since 1991, whereas three out of four regions in the west of the country, Epirus, Western Macedonia, and Western Greece, were during the time period 1991-2004 among the poorest Greek regions in per capita GDP [7].

Greece has been a member of the EU since 1981 and member of the Economic and Monetary Union (EMU) of the EU since June 2000 (officially from 1-12001). The Greek labour force totalled approximately 4.4 million in 2006-also in 2011-and Greece ranks first in the working hours per year ranking of EU countries from 2008 onwards (see Eurostat statistics database at http://epp.eurostat.ec.europa.eu/portal/page/portal/statistics /search_database). In 2008, roughly $66 \%$ of the workforce in Greece was involved in the service sector, $23 \%$ in industry, and $11 \%$ in agriculture [9]. The Greek economy-based on its annual GDP-expanded at an average annual rate of almost 4\% in the time period 2004-2007 (one of the highest rates in the Euro area). Table 2 indicates that, after the introduction of the euro in 2002, Greece displayed the highest GDP growth rate in terms of purchasing power standards (PPS) in 2006. This peak (in terms of rate of growth) in 2006 was explained at that time by "financial market liberalisation coupled with membership in monetary union, which led to a substantial reduction in borrowing costs; buoyant activity in export markets in south-eastern Europe; and the fiscal stimulus and focal point given by the Olympic Games in 2004" [12, page 11].

Recent evidence, however, indicates that this is not the case anymore. Greece suffers from political and economic corruption and low global competitiveness compared to other EU and especially Eurozone countries. By the end of 2009 and especially in the beginning of 2010, as a result of the global crisis and the uncontrolled government spending, huge shadow economy rates and complexed bureaucratic procedures, the Greek economy faced its most severe crisis since 1974. However, the need for sustained fiscal consolidation and the issues of productivity and competitiveness were already known four years ago (see [13]).

The problem of the second economy in the Greek labour market is related to the structure of the economic system and to a large extent to the swelling of the public sector at the expense of the private sector activities; this leads to the increase of the tax burdens in terms of both direct and indirect taxation. This fact and also the existence of an insufficient taxation system which is in force up to now, increase the phenomenon of shadow economy in Greece, with its severe consequences in the labour market and the creation of new investments and new job positions (see [14, page 12] and [15, page 96]). Also, according to the study of the University of Linz [16], the size of the black economy in Greece as a percentage of GDP rose from $24.9 \%$ during the period $1990-1993$ to $28.7 \%$ in 1999 2000. According to the econometric research of Tatsos [17, page 92], from 1960 to 1997 the average value of the underground economy in the Greek labour market as a percentage of GDP was 30.1\%; the shadow economy in Greece from 1960 to 1997 increased by 40.2\% (1960: 26.1\%, 1997: 36.7\%). Paleologos and Kassar [18] estimated the mean value of black economy in Greece at $25.01 \%$ as a percentage of GDP, during the period 1960-2000, with its 
TABLE 1: (a) Unemployment rates (annual average \%). (b) Long-term unemployment rates as percentage of the unemployed people (annual average $\%)$.

(a)

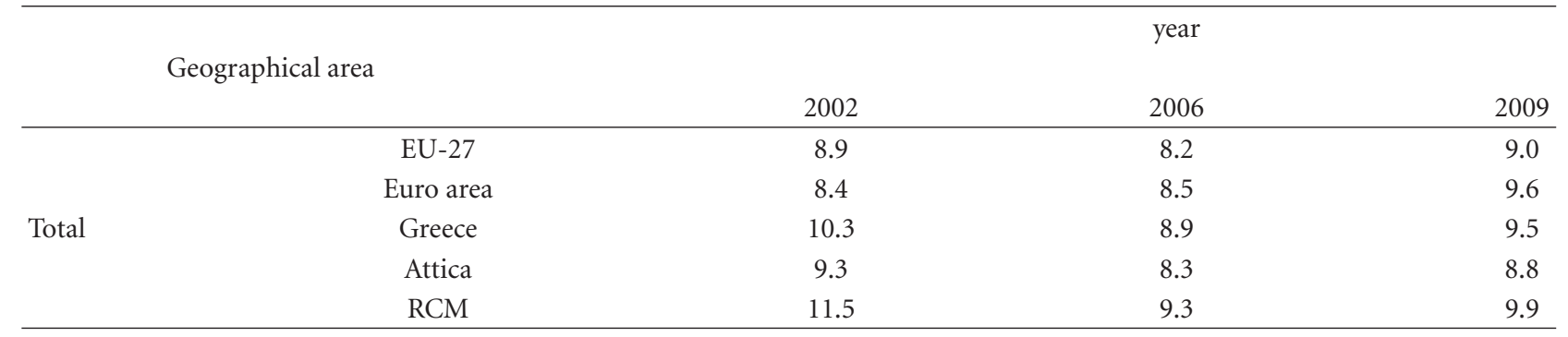

Source: Eurostat (http://www.epp.eurostat.ec.europa.eu/portal/page/portal/statistics/search_database).

(b)

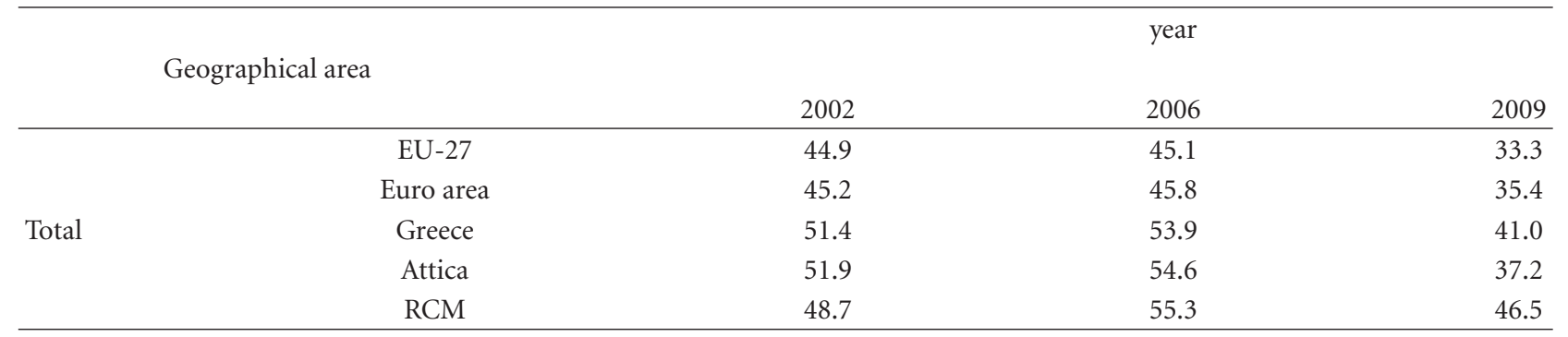

Source: Eurostat (http://www.epp.eurostat.ec.europa.eu/portal/page/portal/statistics/search_database).

maximum value recorded in 2000 (36.67\%); in total, during the period 1960-2000 the size of the second economy in Greece rose by $82.3 \%$. According to Friedrich Schneider, the mean percentage of the underground economy in 21 selected OECD countries equals $13.4 \%$ of the GDP in 2010; the same year in Greece this share was $29.9 \%$ or 69.05 billion euro (source: http://www.express.gr, on 20/05/2011).

3.2. The Region of Central Macedonia (RCM). Central Macedonia is the largest region of Greece $\left(19,147 \mathrm{~km}^{2}, 14.5 \%\right.$ of the country's surface) and is situated in the centre of Northern Greece. The RCM consists of seven NUTS-3 areas (Thessaloniki, Serres, Chalkidiki, Imathia, Pella, Kilkis, and Pieria) and is the second largest Greek region in terms of population (1.87 million inhabitants according to 2001 census) after that of Attica. Also, the major urban centre and capital of Central Macedonia is Thessaloniki, which is the second most important Greek city; according to 2001 census the population of the Thessaloniki area was about 837,000 inhabitants. The main industries were textiles, plastic-chemicals, food-beverages, and clothing. In 2003, the region's per capita GDP (PPS) was 17,110 euro ( $83 \%$ of the EU-25 average), whereas Thessaloniki and Chalkidiki were the richest NUTS-3 areas of the region having a GDP per head equal to $90.3 \%$ and $89.5 \%$ correspondingly of the EU25 mean. In 2003 the region produced $17.6 \%$ of the country's GDP (the second largest contributor after Attica), 18\% of the national agricultural production (first in the country), 20\% of the manufacturing production (second in the country), and $18 \%$ of services (second in the country), (source: ESYE [10]).
3.3. The Region of Attica. The Region of Attica (NUTS2) — which is geographically situated in Central Greece-is the one and only region-county (NUTS-3) in Greece, since according to 2001 census its population size was 3.76 million inhabitants; namely, three out of ten Greeks lived in Attica. The capital of the region is the city of Athens, which is by far the most important Greek city in economic, administrative, and political terms. The population of the Athens area was 3.07 million in 2001. In 1988, Attica's GDP was equal to $61 \%$ of the EU-12 average ( $58 \%$ for Greece as a whole), whereas in 1996 the region improved its position since its GDP was 77\% of the EU-15 mean ( $68 \%$ for the country as a whole) and $86 \%$ of the EU-25 mean in 2003 (80.9\% for Greece as a whole). The region of Attica produces $37.4 \%$ of the country's GDP, $2.7 \%$ of the country's agricultural produce, $35.5 \%$ of the manufacturing, and $42 \%$ of services (2001), (source: ESYE [10]).

\section{Econometric Model: Logistic Regression for Unemployment}

4.1. The Logistic Regression Based on the Microdata of the Greek LFS. European Community Household Panel Survey (ECHPS) and Survey on Income and Living Conditions (SILCs) data have been designed for the country as a whole in the case of Greece, so we cannot really work at regional level. Also, individual census records do not exist in Greece, like, for example, in Denmark, so the only way is to base our research on the LFS microdata.

The originality of this research is that we use individual anonymised records (microdata) of the Greek LFS data in 


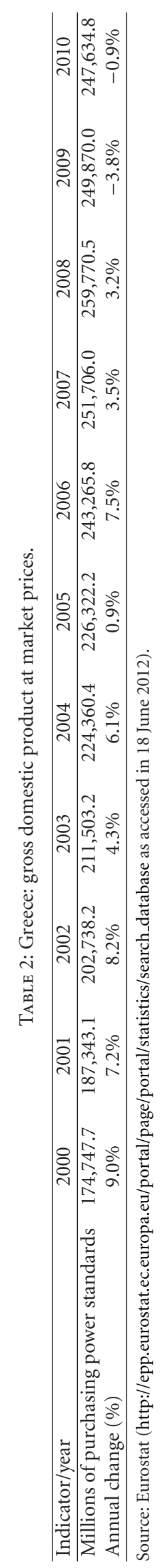


2006 for both employed and unemployed. Until 1997 the LFS sample was equal to $1.5 \%$ of the total population of the country. Since 1998 LFS has been conducted four times a year-instead of once per year until 1997-with a sample of about 80,000 records for the whole country $(0.7 \%$ of the total population) in each of the four quarters [9].

Table 3 shows the numbers of records eligible for analysis in the LFS samples of the two regions under examination and the entire country in 2006. Apart from the system missing records, following the limitation of age (15-64 years old) and removing the nonactive population, we ended with the numbers (Table 2) of records eligible for analysis in each area (in the spring and early summer, namely, from the 14th to 26th week of the year).

The basic aim of the econometric analysis is to test the impact that various social and demographic characteristics had on people's job prospects in the whole of Greece, as well as in the regions of Central Macedonia and Attica, in 2006. We use a logistic regression model. Regression models allow for group comparisons adjusting for demographic and socioeconomic variables. It should be noted that regressionadjusted comparisons may still provide misleading results when other important variables that might have an effect are omitted. The models were fitted using SPSS version 18.0.

The dependent variable takes two possible values (employed versus unemployed). The explanatory variables are gender, age group (four categories), marital status (six), levels of education achieved, area of residence (Athens area, Thessaloniki area, rest of urban areas, semiurban areas, and rural areas), immigrant status, and being registered in the Manpower Employment Organisation (OAED). The working age population is between 14-65 years old. However, marking in SPSS the ages 14 and 65 we also include those who are 13 and 66 years old, something which we want to avoid, so, we include people from 15 to 64 . A full description of the explanatory variables is given below and these variables are among the most important variables generally acknowledged as affecting access to labour market.

The effect of demographic variables such as age, gender, marital status, residence location, immigrant status, and educational level on the employment status is investigated with a logistic regression model due to the categorical nature of the dependent variable. The binary logistic regression equation is

$$
\begin{aligned}
e= & \beta_{0}+\beta_{1} \text { gender }+\beta_{2} \text { m.s. }+\beta_{3-6} \text { a.g. } \\
& +\beta_{7-12} \text { educ. }+\beta_{13-15} \text { res. }+\beta_{16} \mathrm{im},
\end{aligned}
$$

where $e$ (employment status) is the logit (ln of the odds) of being unemployed. The parameter estimates $\beta$ are the odds ratio of the independent variables; $\beta_{0}$ is the constant.

The descriptive statistics for the three areas are summarised in Table 3 (see above). Table 4 presents the estimated coefficients (B) and their standard errors (S.E.) of each explanatory variable in the logistic regression for unemployment. The column "Sig." (level of statistical significance or $P$ value) corresponds to the probability of the rejection area, so coefficients with a value not higher than 0.05 are highly and significantly different from zero. The base (or reference) categories are those that appear in the Table 4 with empty (not asterisked) cells and with which the rest of the corresponding variables are compared. The reference categories are chosen so as to match the needs of the research.

4.1.1. Description of the Variables. We define now the complete list of variables that we use in the model. The reference category of each variable is underlined.

Dependent Variable. Employment status (unemployed, employed).

\section{Explanatory Variables}

(1) Gender (female, male).

(2) Marital status (married or divorced or widows against nonmarried).

(3) Age groups:

$$
\begin{aligned}
& \frac{15-24 \text { years old, }}{25-34 \text { years old, }} \\
& \text { 35-44 years old, } \\
& \text { 45-64 years old. }
\end{aligned}
$$

(4) Level of education:

$$
\begin{aligned}
& \text { M.S. or Ph.D. holders, } \\
& \text { university graduates, } \\
& \text { technological educational institutions (TEIs) } \\
& \text { graduates, } \\
& \text { Lyceum graduates ( } 12 \text { years of schooling) or not } \\
& \text { finishing university, } \\
& \text { high-school graduates ( } 9 \text { years: compulsory } \\
& \text { education), } \\
& \text { primary school graduates or not finishing pri- } \\
& \text { mary school or never in school. }
\end{aligned}
$$

(5) Residence location:

$$
\begin{aligned}
& \text { Athens area, } \\
& \text { Thessaloniki area, } \\
& \text { rest of urban areas, } \\
& \text { semiurban areas, } \\
& \text { rural areas. }
\end{aligned}
$$

(6) Registered in OAED.

(7) Immigrant status.

4.2. Analysis of the Results for Central Macedonia. Table 4 presents the results of the logistic regression in the RCM for 2006. Women, nonmarried individuals, people in the age group 15-24 years old, were more likely to be unemployed than men, married people and people in the age between 25 to 64 . The results are in accordance with the family strategies 
Table 3: Descriptive statistics for Greece, Attica, and RCM.

\begin{tabular}{|c|c|c|c|c|c|c|}
\hline \multirow{4}{*}{ Variables/area } & \multicolumn{6}{|c|}{2006} \\
\hline & \multirow{2}{*}{\multicolumn{2}{|c|}{$\begin{array}{c}\text { Greece } \\
31.898 \text { cases }\end{array}$}} & \multirow{2}{*}{\multicolumn{2}{|c|}{$\begin{array}{c}\text { Attica } \\
8.498 \text { cases }\end{array}$}} & \multirow{2}{*}{\multicolumn{2}{|c|}{$\begin{array}{l}\text { C. Macedonia } \\
4.984 \text { cases }\end{array}$}} \\
\hline & & & & & & \\
\hline & Frequencies & Share & Frequencies & Share & Frequencies & Share \\
\hline Employed & 29.132 & $91,3 \%$ & 7.809 & $91,9 \%$ & 4.504 & $90,4 \%$ \\
\hline Unemployed & 2.766 & $8,7 \%$ & 689 & $8,1 \%$ & 478 & $9.6 \%$ \\
\hline Males & 18.692 & $58,6 \%$ & 4.949 & $58,2 \%$ & 2.584 & $57,3 \%$ \\
\hline Females & 13.206 & $41,4 \%$ & 3.549 & $41,8 \%$ & 2.130 & $42,7 \%$ \\
\hline Marital status & 22.072 & $69,2 \%$ & 5.458 & $64,2 \%$ & 3.477 & $69,8 \%$ \\
\hline Aged 15-24 & 2.666 & $8,4 \%$ & 716 & $8,4 \%$ & 431 & $8,6 \%$ \\
\hline Aged 25-34 & 8.181 & $25,6 \%$ & 2.480 & $29,2 \%$ & 1.275 & $25,6 \%$ \\
\hline Aged 35-44 & 9.004 & $28,2 \%$ & 2.455 & $28,9 \%$ & 1.497 & $30,0 \%$ \\
\hline Aged 45-64 & 12.047 & $37,8 \%$ & 2.847 & $33,5 \%$ & 1.781 & $35,7 \%$ \\
\hline M.S. or Ph.D. holders & 386 & $1,2 \%$ & 213 & $2,5 \%$ & 75 & $1,5 \%$ \\
\hline University graduates & 4.905 & $15,4 \%$ & 1.587 & $18,7 \%$ & 892 & $17,9 \%$ \\
\hline TEI graduates & 4.661 & $14,6 \%$ & 1.750 & $20,6 \%$ & 771 & $15,5 \%$ \\
\hline 12 years of schooling & 10.331 & $32,4 \%$ & 2.848 & $33,5 \%$ & 1.677 & $33,6 \%$ \\
\hline 9 years of compulsory education & 3.690 & $11,6 \%$ & 922 & $10,8 \%$ & 573 & $11,5 \%$ \\
\hline Primary school graduates and below & 7.925 & $24,8 \%$ & 1.178 & $13,9 \%$ & 996 & $20,0 \%$ \\
\hline Athens area & 5.982 & $18,8 \%$ & 5.982 & $70,4 \%$ & - & - \\
\hline Thessaloniki area & 3.042 & $9,5 \%$ & - & - & 3.042 & $61,0 \%$ \\
\hline Urban areas & 10.192 & $32,0 \%$ & 1.569 & $18,5 \%$ & 714 & $14,3 \%$ \\
\hline Semiurban areas & 4.997 & $15,7 \%$ & 809 & $9,5 \%$ & 635 & $12,7 \%$ \\
\hline Rural areas & 7.685 & $24,1 \%$ & 138 & $1,6 \%$ & 593 & $11,9 \%$ \\
\hline Registered in OAED & 2.183 & $6,8 \%$ & 400 & $4,7 \%$ & 386 & $7,7 \%$ \\
\hline Immigrants & 1.915 & $6,0 \%$ & 839 & $9,9 \%$ & 270 & $5,4 \%$ \\
\hline
\end{tabular}

and the gender roles in traditional families in some areas of the region, as well as to the unequal opportunities and discrimination against women by companies. The gender differences could also be attributed to the fact that women often join the labour market earlier. Compulsory military service and further education (not a likely explanation anymore) were the major reasons for men's delay in entering the labour market. Extended family protection, with a view to preparation for entry into the labour market, applies to both sexes, of course.

In addition, for 2006 university graduates (the reference group) were more likely to be employed compared to primary school graduates and M.S. or Ph.D. holders (other differences were not found significant). The 2006 findings partly confirm the human capital theory that the more education one receives the more chances he has in employment. The variable "immigrant status" and all three urbanization categories were found to be statistically nonsignificant in the RCM for 2006. Also, people who were registered in OAED were more likely to be unemployed.

4.3. Analysis of the Results for Attica. Table 4 gives the results of the logistic regression in Attica for 2006. Women, nonmarried individuals, and young people (15-24 years old) were more likely to be unemployed than men, married individuals and people in older age groups. In 2006, university graduates were found to be more likely to be employed compared to lyceum, high-school, and primary school graduates (the variable "TEI graduates" gives nonsignificant results). Those results are in contrast to some studies which assert the opposite (see introduction).

For 2006, the variables of Athens area, semiurban areas, and the rest of urban areas were found to be statistically nonsignificant. This seems reasonable for Attica, sinceas we have already mentioned-Attica is the only regioncounty (NUTS-3) in Greece, so, in Attica, the meaning of urban, semiurban, and rural areas is very relevant. The variable "immigrant status" was found to be statistically nonsignificant in Attica. Also, people who were registered in OAED were less likely to be employed (for econometric evidence for Greek NUTS-2 areas and the entire country evaluated up to 1992, see [19-22] or for Greek NUTS-2 areas evaluated up to 2006 , see $[23,24])$.

4.4. Analysis of the Results for Greece as a Whole. Table 4 presents the results from the logistic regression in Greece as a whole for 2006. Women, nonmarried individuals, people in the age group 15-24 years old, people who lived either in Athens area or Thessaloniki area or the rest of urban areas were more likely to be unemployed than men, married people, people in the age between 25 to 64 and those in rural areas. These results (apart from residence location) 


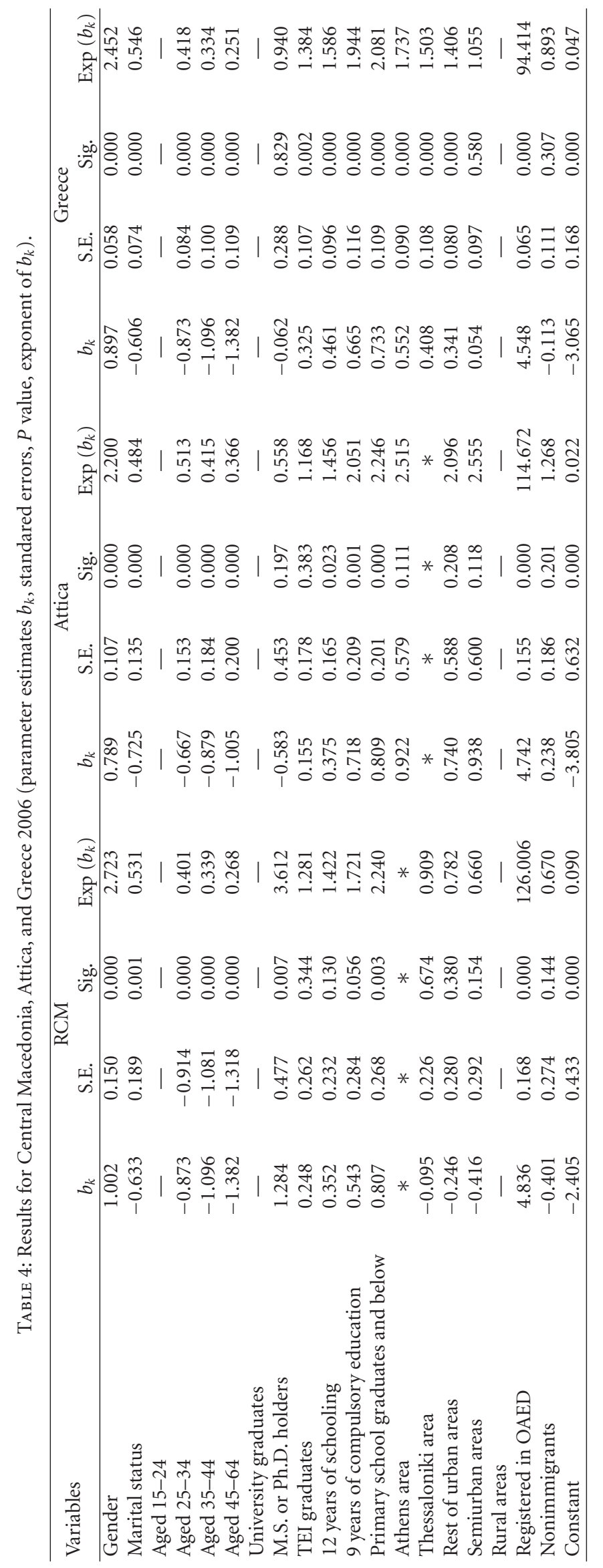


are similar to those for the RCM in 2006. The effect of urbanization level can be explained since in the Greek agrarian sector unemployment was not properly counted, because hidden unemployment is quite high. "Living in semiurban areas" was found to be statistically nonsignificant.

In addition, in 2006 university graduates were less likely to be unemployed compared to all other educational categories apart from M.S. or Ph.D. holders (these differences were not found significant). The 2006 findings confirm the human capital theory that higher education levels increase chances of employment. Also, people who were registered in OAED were more likely to be unemployed. Finally, in 2006 the variable "immigrant status" was found to be statistically nonsignificant.

\section{Conclusions}

According to the findings of the logistic regression, the results for gender, marital status, and age groups are the same in 2006 in both regions and the entire country. Namely, women were more likely to be unemployed than men, the married were less likely to be unemployed than the nonmarried, whereas people in the age group 15-24 years old were found in a worse situation in the labour market in relation to the remaining age categories.

In the domain of education for the RCM in 2006 only primary school graduates and M.S. or Ph.D. holders are statistically significant (less likely to be employed than university graduates). On the contrary for Attica the same is in force only for graduates of primary and secondary education. According to our findings, in the domain of education the results for the entire country in these samples are clear in 2006 apart from M.S. or Ph.D. holders and confirm the human capital theory.

Regarding the residence location for 2006, all three urbanization categories were found to be statistically nonsignificant in both Attica and the RCM. On the contrary, regarding the urbanisation level, the results for Greece as a whole show that for 2006 people who lived in rural areas were in a better position in the labour market than those in the Thessaloniki area, Athens area, and the rest of urban areas; only the variable "living in semiurban areas" is statistically nonsignificant.

The variable "immigrant status" was found to be statistically nonsignificant in 2006 in both regions and the entire country as well. Also, in 2006, in Greece as a whole and in both regions, people who were registered in OAED were less likely to be employed.

The research would merit attention of a wider international readership, since the paper does offer evidence that could be useful for comparative research among European countries and regions. The econometric research of Rodokanakis et al. [19-24] from 1988 up to 2006 shows that variables like gender, age, marital status, being registered in OAED, and participation in training programme gives in general the same results at both national and NUTS-2 level (training does not alter the prospects of individuals of getting a job; in the 2006 LFS detailed information on training is not available); however, concerning the level of education, residence location, and immigrant status, the econometric evidence varies according to year and area of research. Further research could compare the period 19882006 with the years of the deep economic crisis in Greece (2009-2012) and examine the similarities and differences of the fore-mentioned or other variables.

\section{References}

[1] C. Meghir, Y. Ioannides, and C. Pissarides, "Female participation and male unemployment duration in Greece. Evidence from the labour force survey," European Economic Review, vol. 33, no. 2-3, pp. 395-406, 1989.

[2] OECD, Employment Outlook, OECD, Paris, France, 1990.

[3] N. Iliades, "Continuing vocational training in Greece," National Report (in the Context of FORCE), National Institute of Labour, 1995.

[4] IN.E./GSEE (Institute of Labour/General Confederation of Workers of Greece)—ADEDY (Civil Servants' Supreme Administrative Council), "The Greek economy and the employment," Annual Report 1, Athens, Ga, USA, 1999 (in Greek).

[5] Ch. Katsikas, Studies-Vocation and Labour Market, Atrapos Publishing, Athens, Ga, USA, 2005.

[6] E. L. Ioakimoglou, "The macro-economic policy and the unemployment," in Unemployment, Economic Policy and Employment Policies, Notebooks of IN.E no. 4, pp. 7-25, IN.E./GSEE, Athens, Ga, USA, 1995.

[7] EUROSTAT, “Unemployment in the EU," No. 7, 1997.

[8] IN.E./GSEE-ADEDY, "The Greek economy and the employment," Annual Report 2, Athens, Ga, USA, 2000 (in Greek).

[9] ESYE (National Statistical Service of Greece, 1988-2006), "Statistical Yearbook and Labour Force Survey".

[10] ESYE, http://www.statistics.gr.

[11] IMF, World Economic Outlook Database, 2009.

[12] OECD, OECD Economic Surveys: Greece 2007, OECD, Paris, France, 2007.

[13] OECD, OECD Economic Surveys: Greece 2005, OECD, Paris, France, 2005.

[14] M. Negreponti-Delivani, The Economy of Black Economy in Greece, Papazisis Publishers, Athens, Ga, USA, 1990.

[15] I. Vavouras, N. Karavitis, and A. Tsouchlou, "The consequences of economic activity of public sector to the development of the underground economy: the case of Greece," Studies in Honour of Prof. A. Kanellopoulos, Spoudai, University of Piraeus, Piraeus, Greece, vol. A, pp. 90-99, 1992 (in Greek).

[16] University of Linz, "Study on the informal economy in OECD countries during the period 1999-2000 (the results were announced by the European Commission in Brussels," 2001.

[17] N. Tatsos, Shadow Economy and Tax Evasion in Greece, IOVE, Papazisis Publishers, Athens, Ga, USA, 2001.

[18] I. Paleologos and G. Kassar, "Assessment of the size of shadow economy in Greece 1960-2000," Spoudai, vol. 53, no. 3, pp. 14-36, 2003.

[19] S. Rodokanakis, "Investigating the unemployment risk of Central Macedonia in Greece from the LFS individual anonymised records," The Empirical Economics Letters, vol. 8, no. 1, pp. 3543, 2009.

[20] S. Rodokanakis, "Comparing the probability of unemployment in Southern Greece vis-à-vis the entire country," Bulletin of Geography, vol. 12, pp. 17-43, 2009. 
[21] S. Rodokanakis and D. Tryfonidis, "Unemployment hazard in the Aegean islands: econometric analysis of the LFS microdata," in The Global Economics of a Changing Environment: Studies in the Structure, Performance and Reform of Economics, Organizations and Business throughout the Globe, J. A. Brox and N. Baltas, Eds., chapter 14, pp. 211-224, North Waterloo Academic Press, Waterloo, Canada, 2009.

[22] S. Rodokanakis, "The dynamics of regional labour markets and training programmes: Greek evidence," European Spatial Research and Policy, vol. 17, no. 1, pp. 93-115, 2010.

[23] S. Rodokanakis and V. Vlachos, "Assessing the probability of employment in Greece between the 2004 Olympics and the global financial crisis: the cases of the Northern Aegean and Ionian islands," International Journal of Employment Studies. In press.

[24] S. Rodokanakis and V. Vlachos, "Measuring the unemployment risk in Northern Greece from the LFS micro-data during the period 1994-2006," The Review of Economic Analysis. In press. 


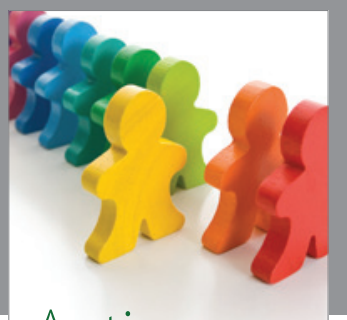

Autism

Research and Treatment
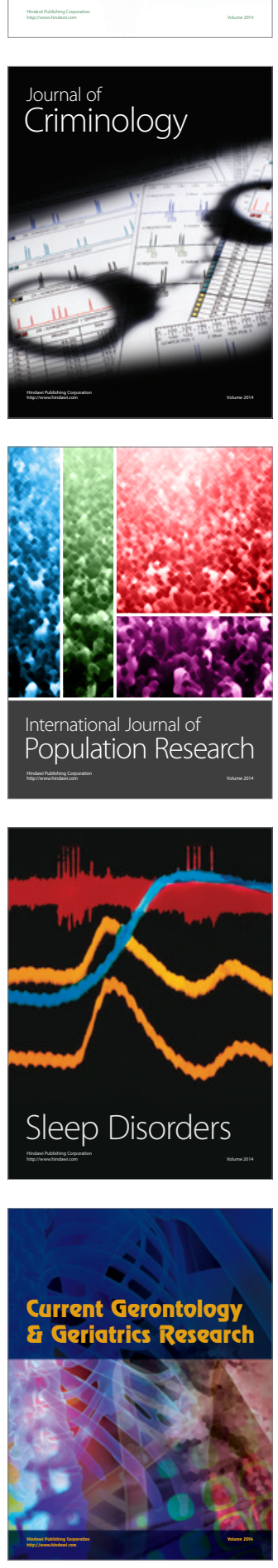
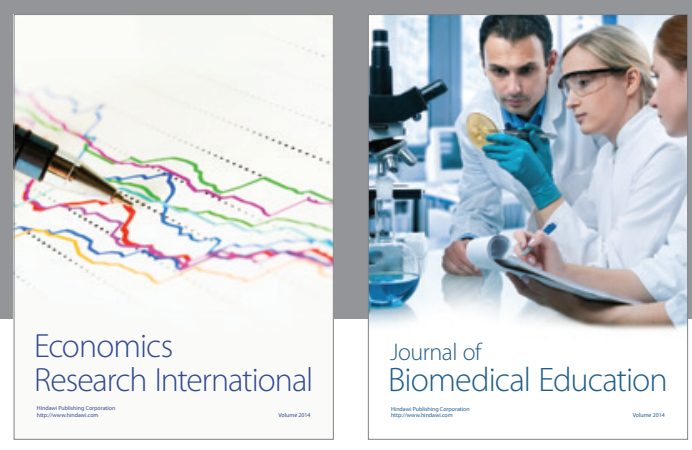

Journal of

Biomedical Education

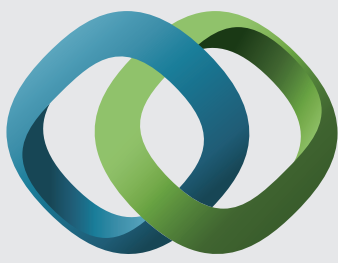

\section{Hindawi}

Submit your manuscripts at

http://www.hindawi.com
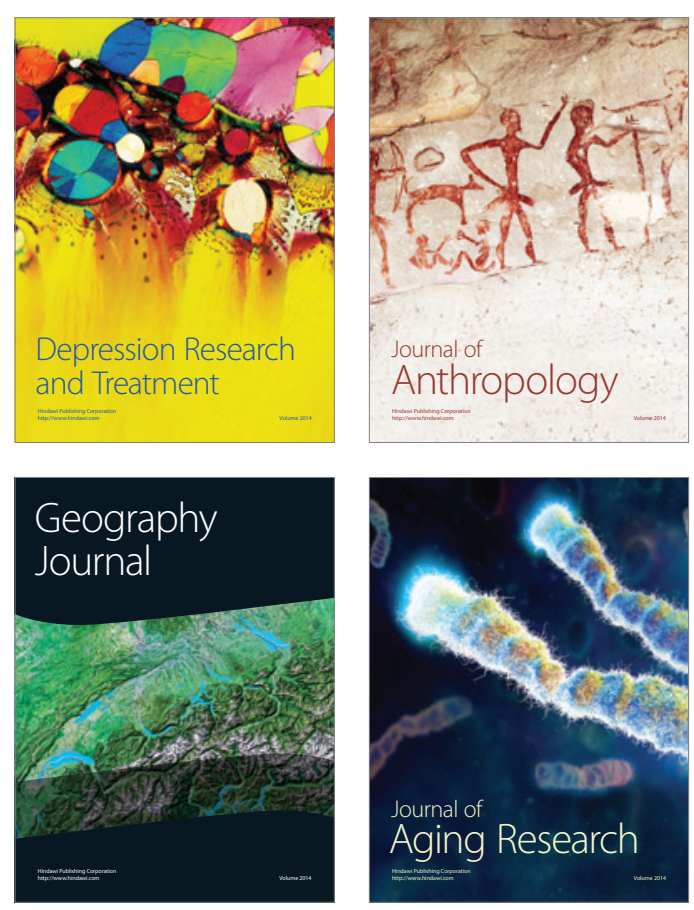

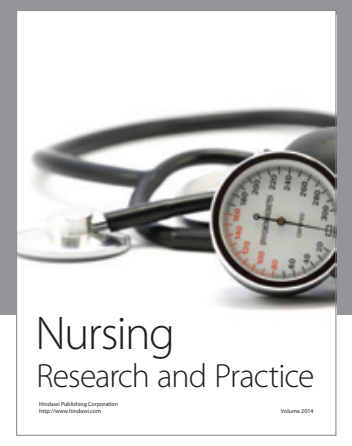

Nursing

Research and Practice

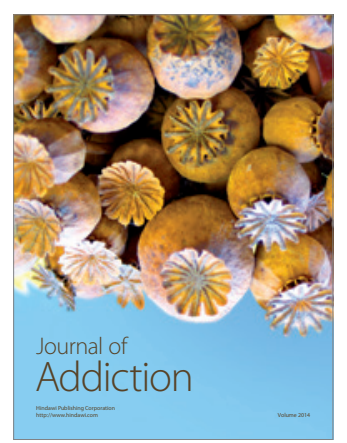

Child Development

Research

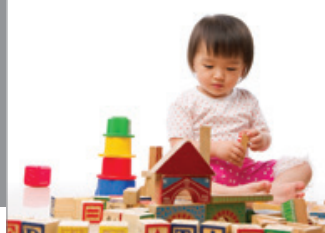

迥
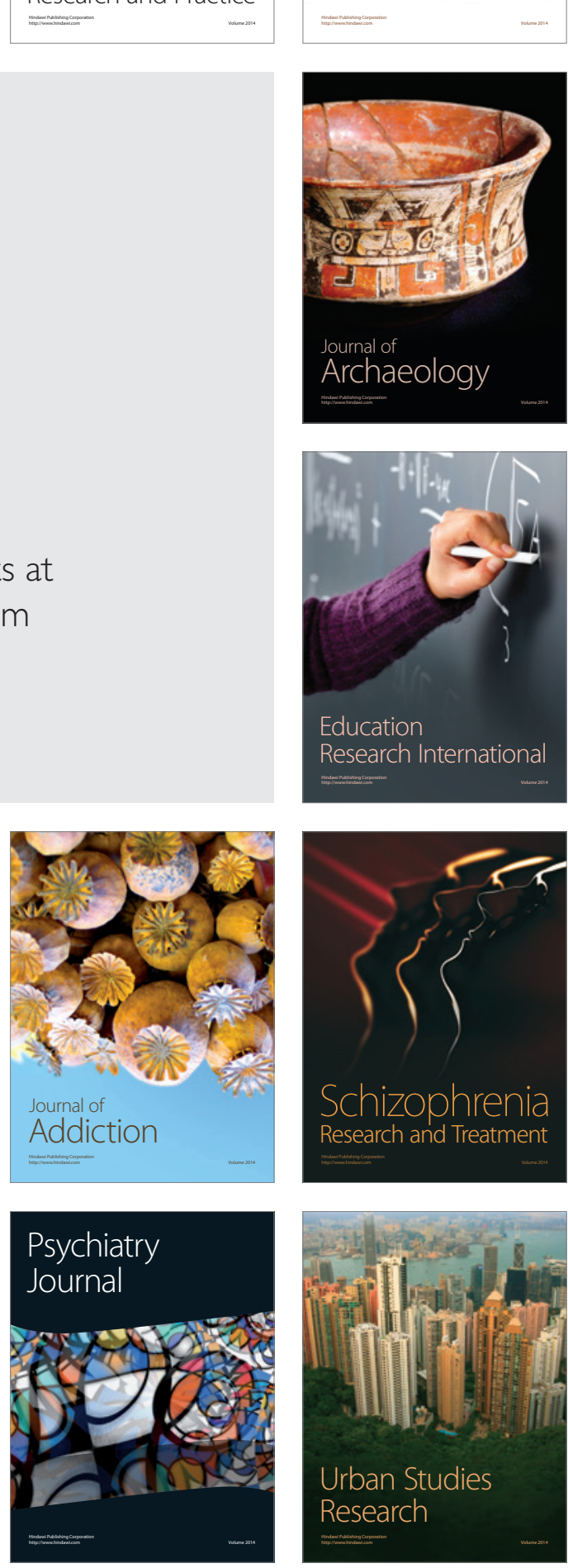